\title{
Malaria in the state of Rio de Janeiro, Brazil, an Atlantic Forest area: an assessment using the health surveillance service
}

\author{
Renata Bortolasse Miguel'1, Paulo Cesar Peiter', Hermano de Albuquerque', \\ José Rodrigues Coura', Patrícia Ganzenmüller Moza², Anielle de Pina Costa ${ }^{3}$, \\ Patricia Brasil ${ }^{3}$, Martha Cecília Suárez-Mutis ${ }^{1 /+}$
}

\author{
${ }^{1}$ Laboratório de Doenças Parasitárias, Instituto Oswaldo Cruz ${ }^{3}$ Instituto de Pesquisa Clínica Evandro Chagas-Fiocruz, \\ Rio de Janeiro, RJ, Brasil ${ }^{2}$ Gerência de Doenças Transmitidas por Vetores e Zoonoses, Secretaria de Saúde e Defesa Civil \\ do Estado do Rio de Janeiro, Rio de Janeiro, RJ, Brasil
}

The lethality of malaria in the extra-Amazonian region is more than 70 times higher than in Amazonia itself. Recently, several studies have shown that autochthonous malaria is not a rare event in the Brazilian southeastern states in the Atlantic Forest biome. Information about autochthonous malaria in the state of Rio de Janeiro (RJ) is scarce. This study aims to assess malaria cases reported to the Health Surveillance System of the State of Rio de Janeiro between 2000-2010. An average of 90 cases per year had parasitological malaria confirmation by thick smear. The number of malaria notifications due to Plasmodium falciparum increased over time. Imported cases reported during the period studied were spread among $51 \%$ of the municipalities (counties) of the state. Only 35 cases (4.3\%) were autochthonous, which represents an average of 3.8 new cases per year. Eleven municipalities reported autochthonous cases; within these, six could be characterised as areas of residual or new foci of malaria from the Atlantic Forest system. The other 28 municipalities could become receptive for transmission reintroduction. Cases occurred during all periods of the year, but $62.9 \%$ of cases were in the first semester of each year. Assessing vulnerability and receptivity conditions and vector ecology is imperative to establish the real risk of malaria reintroduction in $R J$.

Key words: malaria - surveillance - Atlantic Forest - P. vivax - P. falciparum

In Brazil, $99 \%$ of malaria cases occur in the Amazon Region. The disease is occasionally reported outside Amazonia, especially in areas of the Atlantic Forest biome such as the state of Rio de Janeiro (RJ) (Mattos et al. 1993). Moreover, most cases in the extra-Amazonian region are imported from endemic areas of Brazil or other countries (Couto et al. 2010) In 2009, approximately 200 cases were considered autochthonous (MS/SVS 2013).

In RJ, in the Southeast Region of Brazil, malaria was a serious public health problem in the first part of the XX century (Hochman et al. 2002). One of the most important malaria endemic areas in the country was Baixada Fluminense (Hochman et al. 2002), part of the RJ Metropolitan area. This area of 2,783.2 $\mathrm{km}^{2}$ now has 3.5 million inhabitants (of whom, approximately $90 \%$ live in urban areas) and 12 municipalities. By 1944, 33 out of 56 municipalities in the state were considered endemic for malaria (Carvalho \& Rachou 1950) and four naturally infected vector species were found, namely, Anopheles darlingi, Anopheles aquasalis, Anopheles albirtarsis and Anopheles bellator (Carvalho \& Rachou 1950). In 1947 , the number of malaria cases decreased due to the

doi: 10.1590/0074-0276130558

Financial support: FAPERJ, CAPES

+ Corresponding author: marmutis@ioc.fiocruz.br

Received 2 December 2013

Accepted 28 May 2014
National Malaria Service campaigns. With the implementation of the Global Malaria Eradication Program (GMEP) in Brazil in the 1960s, the fight against malaria had been strengthened in RJ by 1965 and transmission was considered interrupted in 1968 (Moraes 1990). Between 1945-2010, 79 countries were able to successfully eliminate malaria as a result of the GMEP. Nevertheless, in a recent systematic review, Cohen et al. (2012) described 75 resurgence events in 61 countries. The causes of these malaria resurgences are poorly studied, but some hypotheses have been proposed.

Several recent studies have shown that autochthonous malaria is not a rare event in the southeast states of Brazil's Atlantic Forest biome (Mattos et al. 1993, Cerutti Jr et al. 2007, Couto et al. 2010). For instance, local malaria cases have been reported in the states of São Paulo (SP) (Wanderley et al. 1994, Branquinho et al. 1997, Couto et al. 2010), Espírito Santo (ES) (Cerutti Jr 2007), Minas Gerais (MG) (Chaves et al. 1995), Santa Catarina (SC) (Machado et al. 2003) and Paraná (PR) (Bértoli \& Moitinho 2001, Falavigna-Guilherme et al. 2005). However, there is scarce information about autochthonous malaria in RJ. This study aimed to assess malaria cases reported to the Health Surveillance System of the State of Rio de Janeiro in the period between 2002-2010 to investigate whether reintroduction of the disease in the state may have occurred.

\section{SUBJECTS, MATERIALS AND METHODS}

Study area - RJ is located in the Tropical Zone of Southeast Region of Brazil, between 20 $0^{\circ} 4^{\prime}-23^{\circ} 22^{\prime} \mathrm{S}$ $40^{\circ} 57^{\prime}-44^{\circ} 53^{\prime} \mathrm{W}$; it has an area of $43,780 \mathrm{~km}^{2}$ and $92 \mathrm{mu}-$ nicipalities with a population of $15,993,583$ inhabitants 
(IBGE 2010). The state is divided into eight administrative regions: coastal plains, south-central Rio, Green Coast, middle Paraíba, Metropolitan, northwest, north and highlands (Linhares 2011). The topography is characterised by two main geomorphological units: highlands (serras) and lowlands (baixadas). The highlands peak at approximately $3,000 \mathrm{~m}$ above sea level (Pico das Agulhas Negras), whereas the lowlands predominate along the oceanfront, forming various natural bays.

This complex relief not only influences temperatures, but also rainfall distribution, resulting in a highly diverse climate. Average annual rainfall ranges from $900 \mathrm{~mm}$ in the northern part of the state to 2,600 $\mathrm{mm}$ on the slopes of the Serra do Mar and Mantiqueira mountain ranges. Generally, rainfall is evenly distributed with very wet summers and dry winters. Nevertheless, the southern region and mountain slopes facing the ocean are wetter and the northern region is drier throughout the year(INEA 2011). The climate is tropical rainy (Köppen Climate System), typical of the Atlantic Forest, with rainy days almost every month; the rainy season occurs from November-January and the dry season from May-September(IBGE 2010).

In the lowlands such as the Guanabara Bay region, temperatures are usually higher. Monthly average temperatures range from $21.1^{\circ} \mathrm{C}$ in July to $27.3^{\circ} \mathrm{C}$ in January, whereas the minimum temperature is recorded in the dry season $\left(\mathrm{ca} .14^{\circ} \mathrm{C}\right)$ and the maximum temperature in the rainy season $\left(\mathrm{ca} .40^{\circ} \mathrm{C}\right.$ ). In highlands such as the Serrana Region, monthly average temperatures range from $20-24^{\circ} \mathrm{C}$. Because of the climatic diversity, the State Environmental Institute (INEA) in RJ (INEA 2011) divides the territory into seventeen bioclimatic zones according to rainfall, temperature and water balance.

The original vegetation of RJ consisted of Atlantic Forest formations (INEA 2011), which can be divided into rain forest, Araucaria forest, semideciduous forest, steppe and pioneer formations (sandbanks, mangroves, swamps and floodplains). That ecosystem originally covered $98.6 \%$ of the state territory, but currently the forest covers only $17 \%$ of the area, at different stages of preservation (INEA 2011).

Study design and data collection - A descriptive analysis was performed using data from the Epidemiological Surveillance Program of the Health Service of the State of Rio de Janeiro collected between 2002-2010 (available information). The data were kindly provided by the Vector-Borne Diseases and Zoonosis Department of the Health Service of the State of Rio de Janeiro.

Malaria is an obligatory notifiable disease in the entire country and all cases (suspicious or confirmed) must be reported to the National Epidemiological Surveillance System. All suspicious cases must be referred to a health facility and a thick smear must be collected and analysed by an expert microscopist. Diagnosis is based on thick smear findings standardised by the national program and cases are diagnosed as Plasmodium falciparum, Plasmodium vivax, Plasmodium malariae, Plasmodium ovale and mixed infection. Infected individuals are treated with standard medicines distributed free of charge by the National Malaria Control Program (PNCM) (MS/SVS 2003). In the extra-Amazonian re- gion, all cases must be investigated to determine the origin of the case. Case definitions used in this study were adapted from World Health Organization (WHO) recommendations: imported case (infection not locally contracted), induced case (a case induced by transfusion with infected blood), introduced case (infection contracted from an imported case), relapsing case (a $P$. vivax old episode contracted some time ago) and autochthonous cases (a case contracted locally by mosquitoes bites) (WHO 2007). Cases were notified using a PNCM notification form (MS/SVS 2003).

Data analysis - Two different databases were available for analysis. One database had information from 2002-2006 and the other from 2007-2010. These two databases were combined to generate the final data that were imported into EPI-INFO software v.3.5.1 (Center for Disease Control, Atlanta, USA). The data consisted of demographics (age and sex), spatial (municipality of residence and probable infection site), temporal (month and year of infection) and parasitological (parasite species) variables. Descriptive analysis was performed. Proportions were compared using $\chi^{2}$ test. Continuous variables were compared using Mann-Whitney $U$ test. In all cases, a $p$-value $<0.05$ was considered statistically significant. Graphs and tables were created to illustrate malaria trends. A thematic map of the total number of malaria cases in the period was constructed. The municipalities were then classified into six ranges: zero cases, one case, from two-nine cases, from 10-19 cases, from 20-40 cases and $>40$ cases. The map used a territorial database from the Brazilian Institute of Geography and Statistics (IBGE 2010) and malaria data of the Secretary of Health of Rio de Janeiro (CEPA 2009). The map was constructed using Terraview 4.2 ${ }^{\circledR}$ software (INPE 2013).

Ethical considerations - Ethical clearance was provided by the Research Ethical Committee of the Institute of Clinical Research Evandro Chagas at Oswaldo Cruz foundation (protocol: 0229.0.000.009-10). All data analysed in the study were extracted from the Health Surveillance System of the State of Rio de Janeiro malaria information system. No further information was sought from the patients. Informed consent was not required because the data were analysed anonymously.

\section{RESULTS}

Malaria cases in RJ - From 2002-2010, 2,322 suspicious malaria cases were reported to the Epidemiological Surveillance Program. A total of 808 cases (34.8\%) had parasitological confirmation by thick smear, which represents an average of 90 cases per year. The lowest number of cases was reported in 2002 (33 notifications) and the highest in 2006 (128 cases). An increasing trend in the number of reported cases was observed until 2006, whereas a decrease occurred in 2007 and the curve remained stable over the last three years of the study period with an average of 80 cases per year (Fig. 1).

The cases were diagnosed more frequently in men (76.5\%, 618/808). Patients were an average $41.7 \pm 14.6$ years old [95\% confidence interval (CI) 95\%: 40.4842.59]. The youngest patient was two years old and the oldest 86 years old. Only $1.1 \%$ of all malaria patients were 


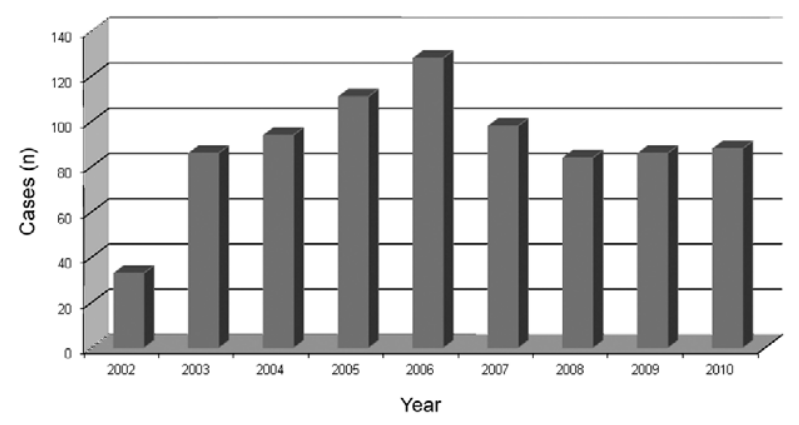

Fig. 1: malaria cases reported in the state of Rio de Janeiro, 20022010. Source: Vector-Borne Diseases and Zoonosis Department of the Health Service of the State of Rio de Janeiro.

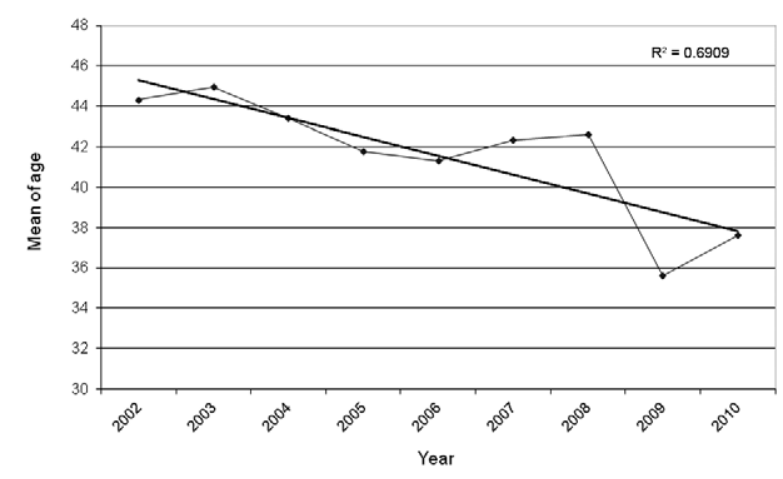

Fig. 2: average of age of cases of malaria in the state of Rio de Janeiro, 2002-2010. Source: Vector-Borne Diseases and Zoonosis Department of the Health Service of the State of Rio de Janeiro.

children under 10 years of age. The mean age among females was $38.12 \pm 16.37$ (95\% CI: 35.71-40.52) years old and among males was $42.49 \pm 14.32$ (95\% CI: 41.3443.65) years old and the difference was statistically significant $(\mathrm{p}=0.0005)$. In addition, a progressive reduction in the mean age of malaria patients over the years was observed: in 2002, the mean age was $44.3 \pm 14.6$ years old and in 2010, $37.6 \pm 16.0$ years old $(\mathrm{p}=0.000304)$ (Fig. 2).

Of the 808 malaria cases reported, 397 (49.1\%) were caused by $P$. falciparum, $382(47.3 \%)$ by $P$. vivax, 21 $(2.6 \%)$ cases were mixed infection (P. falciparum and $P$. vivax) and eight cases $(1 \%)$ were caused by $P$. malariae. $P$. vivax was the most frequently diagnosed parasite among males (307/618, 49.7\%), whereas its frequency among women was $39.5 \%(75 / 190)$ and this difference was statistically significant $(\mathrm{p}=0.010)$. Conversely, there was no difference in $P$. falciparum infection between the sexes $(\mathrm{p}=0.0533)$. Moreover, the number of malaria notifications due to $P$. falciparum increased over time: $39.5 \%$ of reported malaria cases in 2002 and $68.2 \%$ of cases in 2010 were due to $P$. falciparum ( $\mathrm{p}=0.0039)$ (Fig. 3). Of the reported cases, 555 individuals (68.7\%) lived in 47 municipalities (51.1\%) of RJ: 310 individuals ( $38.4 \%$ of all reported cases) lived in the city of Rio de Janeiro, whereas the remaining 245 cases (30.3\%) lived in 46 other municipalities such as Niterói (28 cases, $3.5 \%$ ), Nova Iguaçu, (24 cases, $3 \%$ ), Duque de Caxias (24 cases, $3 \%$ ), Macaé (17 cases, 2.1\%), Nova Friburgo (14 cases,

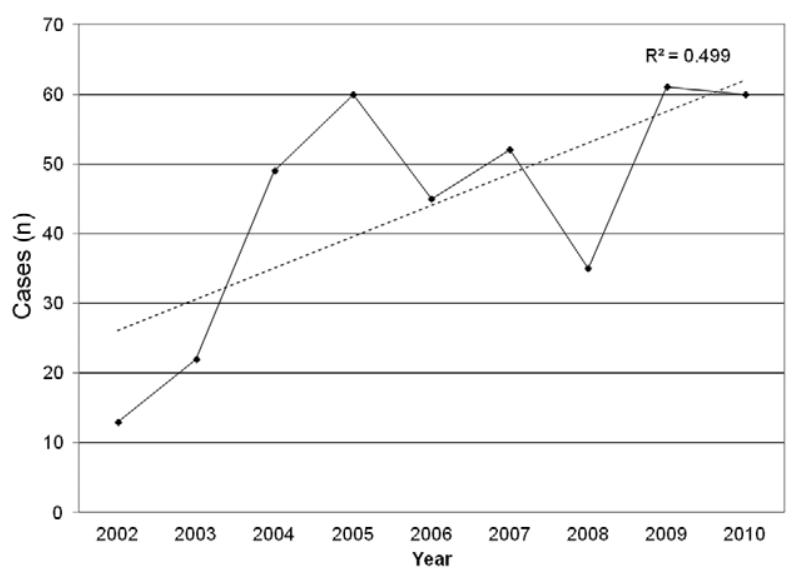

Fig. 3: number of cases diagnosed of Plasmodium falciparum in the state of Rio de Janeiro, 2002-2010. Source: Vector-Borne Diseases and Zoonosis Department of the Health Service of the State of Rio de Janeiro.

1.7\%), Cachoeira de Macacu (14 cases, 1.7\%) and São João de Meriti (11 cases, 1.4\%) (Fig. 4). One hundred seventy-one infected individuals (21.2\%) lived outside $\mathrm{RJ}$; most lived in the states of Amazonas (AM) (10.1\%, $82 / 808)$ and Rondônia (RO) $(4.1 \%, 33 / 808)$ or Pará (PA) $(2.1 \%, 17 / 808)$ (Fig. 4). Lastly, 82 (10.1\%) individuals had no fixed residence and came from other countries.

Of the total 808 cases, 773 were imported. Information about the local of possible infection was obtained only in $226(29.2 \%)$ imported cases. From these, $63.3 \%$ $(143 / 226)$ acquired malaria in the Brazilian Amazon Region, mainly AM, 46.9\% (67/143), RO, 20.3\% (29/143) and PA, 14\% (20/143). A further 83 cases acquired malaria outside Brazil: Africa, 34.9\% (29/83), South-East Asia Region, 31.3\% (26/83), Eastern Mediterranean Region, $15.7 \%$ (13/83), America, 12\% (10/83) and Western Pacific Region, 7.2\% (6/83).

Autochthonous malaria in $R J$ - Of the 808 reported cases in the period, only 35 (4.3\%) were considered autochthonous to RJ, which represents an average of 3.8

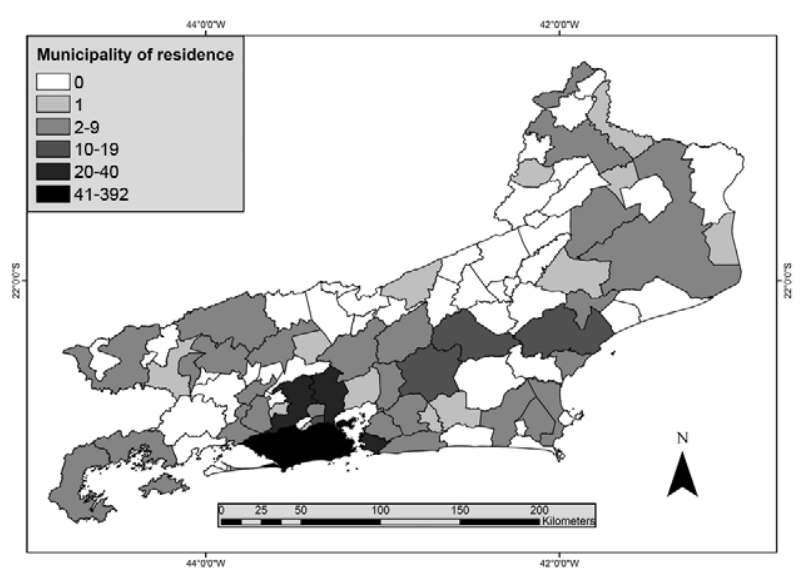

Fig. 4: municipality of residence of imported and autochthonous malaria cases in the state of Rio de Janeiro, 2002-2010 (cases per municipality). Source: Vector-Borne Diseases and Zoonosis Department of the Health Service of the State of Rio de Janeiro. 
TABLE

Municipality of probable source of infection of Plasmodium spp in the state of Rio de Janeiro, according to the parasite species - 2002-2010

\begin{tabular}{|c|c|c|c|c|c|}
\hline $\begin{array}{l}\text { Probable municipality } \\
\text { of infection }\end{array}$ & $\begin{array}{l}\text { Total } \\
\text { (n) }\end{array}$ & $\begin{array}{l}\text { P. vivax } \\
\text { (n) }\end{array}$ & $\begin{array}{l}\text { P. falciparum } \\
\text { (n) }\end{array}$ & $\begin{array}{l}\text { P. malariae } \\
\text { (n) }\end{array}$ & $\begin{array}{c}\operatorname{Mixt}(\mathrm{Pv}+\mathrm{Pf}) \\
\text { (n) }\end{array}$ \\
\hline Cachoeira de Macacu & 8 & 5 & 0 & 3 & 0 \\
\hline Campos dos Goytacazes & 1 & 1 & 0 & 0 & 0 \\
\hline Casimiro de Abreu & 1 & 1 & 0 & 0 & 0 \\
\hline Macaé & 1 & 1 & 0 & 0 & 0 \\
\hline Magé & 1 & 1 & 0 & 0 & 0 \\
\hline Nova Friburgo & 6 & 6 & 0 & 0 & 0 \\
\hline Paraty & 3 & 2 & 0 & 1 & 0 \\
\hline Petrópolis & 1 & 1 & 0 & 0 & 0 \\
\hline Rio das Flores & 1 & 1 & 0 & 0 & 0 \\
\hline Rio de Janeiro & 7 & 3 & $3^{a}$ & 0 & 14 \\
\hline Santa Maria Madalena & 1 & 1 & 0 & 0 & 0 \\
\hline São Fidélis & 4 & 3 & $1^{a}$ & 0 & 0 \\
\hline Total & 35 & 26 & $4^{a}$ & 4 & 1 \\
\hline
\end{tabular}

$a$ : with available data there is no evidence of the true status (autochthonous or not) of these cases in the state. Source: VectorBorne Diseases and Zoonosis Department of the Health Service of the State of Rio de Janeiro.

cases per year. Notifications were made every year, except 2009 , and $68.6 \%$ of the cases were reported between 2003-2005. Eleven municipalities (12\%) reported autochthonous cases. Cachoeira de Macacu was the municipality with the most notifications ( 8 cases, $22.7 \%$ ), followed by Rio de Janeiro ( 7 cases, 20\%), Nova Friburgo (6 cases, 17.1\%), São Fidélis (4 cases, 11.4\%) and Paraty (3 cases, 8.6\%) (Fig. 5). Most autochthonous cases were from men $(31 / 35,93.9 \%)$. Two cases had no gender registration. All reported cases were individuals older than 15 years, with one individual (3\%) under 20 years old, $11(33.3 \%)$ were $20-44$ years old, $11(33.3 \%) 45-59$ years old and $10(30.3 \%) 60$ years or older. The mean age was $49.6 \pm 17.3$ years old (95\% CI: 43.6-55.8). This value is different from the mean age of all malaria cases reported in the state $(41.7 \pm 14.6, \mathrm{p}=0.001)$.

During the period, autochthonous malaria in $\mathrm{RJ}$ was due to $P$. vivax $(27 / 35,77.1 \%), P$. falciparum $(4 / 35,11.4 \%)$ and $P$. malariae $(4 / 35,11.4 \%)$. In addition, one mixed malaria by $P$. vivax and $P$. falciparum was diagnosed. Table shows the distribution of species according to possible infection site of the case. The median time between the onset of symptoms and diagnosis was seven days (1 and 3 interquartile range: $3.5-13.5)$. Cases occurred during all periods of the year, but $62.9 \%$ of notifications were made in the first semester of each year during the summer and autumn. In fact, there were significant differences in the number of malaria cases between the first and second semesters of the year, for the entire study period $(\mathrm{p}=0.031)$. The surveillance system reported 10 deaths by malaria during the period of study with a lethality of 1.23 cases per 100 inhabitants. Municipalities that notified deaths by malaria were: Rio de Janeiro, Magé, Niterói, Petrópolis, Rio Claro, São João de Meriti and Tanguá.

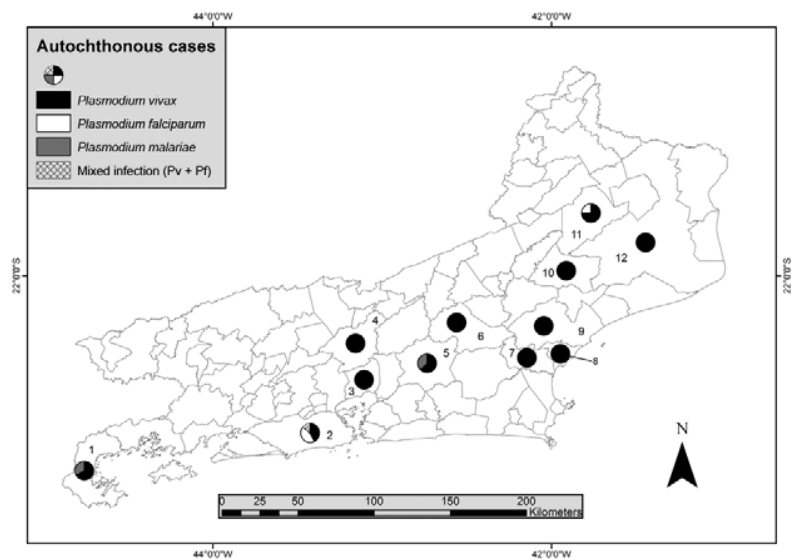

Fig. 5: municipality of probable infection of autochthonous malaria cases in the state of Rio de Janeiro, 2002-2010. 1: Paraty; 2: Rio de Janeiro; 3: Magé; 4: Petrópolis; 5: Cachoeiras de Macacu; 6: Nova Friburgo; 7: Casimiro de Abreu; 8: Rio das Ostras; 9: Macaé; 10: Santa Maria Madalena; 11: São Fidélis; 12: Campos dos Goytacazes. Source: Vector-Borne Diseases and Zoonosis Department of the Health Service of the State of Rio de Janeiro.

\section{DISCUSSION}

$\mathrm{RJ}$ is one of the most important and developed states in Brazil (IBGE 2010). Currently, the state is not considered an endemic malaria area, although over $50 \%$ of municipalities were highly endemic in the first 50 years of the XX century (Costa et al. 2010). Although in 1968 the disease was considered interrupted in the state after implementation of the GMEP (Moraes 1990), sporadic cases continued to be reported to the health surveillance system. Thus, we performed an analysis of data from the 
health surveillance program to assess some of the potential variables involved in the risk of malaria reintroduction in this supposedly interrupted setting. Nevertheless, all secondary information must be reviewed with caution because under-notification is a cause of concern.

It should be noted that an average of 258 suspicious cases were reported per year in the state and on average almost $90(34.8 \%)$ of these cases were parasitologically confirmed each year. Of the 808 confirmed cases in the period, only 35 (4.3\%) were considered autochthonous, but a greater number of cases were not epidemiologically confirmed. In fact, a higher number of autochthonous cases may have been underestimated by the surveillance system and data by Costa et al. (2010) supports this notion.

Men were the most affected by malaria in this study (76.5\% of all cases). This result supports other studies conducted in SP (Wanderley et al. 1985, 1994), MG (Chaves et al. 1995) and SC (Machado et al. 2003). The higher proportion of malaria cases in men may be because they travel to endemic areas to work in high-risk occupations such as mining, farming and timber extraction (Alves et al. 2000). Although the highest proportion of malaria cases in the Amazon still occurs among men, the percentage decreased from $65.1 \%$ in 2003 to $61.4 \%$ in 2008, showing significant differences in the period ( $\mathrm{p}$ $=0.000)($ Couto et al. 2010, MS/SVS 2013).

Although the proportion of cases among children under 10 years of age has increased in Brazil (25.2\% in 2008) (Couto et al. 2010), our results show that only $1.1 \%$ of children had been infected in RJ and no autochthonous cases were reported in this age group. In fact, in our study the overall mean age of patients was $41.7 \pm 14.6$ years old and when only autochthonous cases were considered the average age increased to $49.6 \pm 17.3$ years old $(p=0.0019)$.

Another important question is that while in Brazil $83.7 \%$ of malaria cases are produced by $P$. vivax (Oliveira-Ferreira et al. 2010), our data show that only $47.3 \%$ of cases reported in this extra-Amazonian region were caused by this species and that $P$. falciparum was responsible for $49.1 \%$ of cases during the period. Interestingly, we observed that $P$. falciparum cases increased from $39.4 \%$ in 2002 to $68.2 \%$ in 2010 . This may be because most cases are imported not only from the Brazilian Amazon, but also from areas in African countries and Haiti where P. falciparum is more prevalent. Indeed, a study of the migratory profile of Brazilians shows that high concentrations of individuals who come from African countries are coming to live in the city of Rio de Janeiro (MTE 2009). Additionally, in the past decade, an increased flow of Brazilians who travel to African countries for business or tourism (MTE 2009) has been observed. Similar evidence has been demonstrated for the United Kingdom (Zuckerman 2008) and Canada (Nelder et al. 2013). The greater number of P. falciparum imported cases in these countries has been attributed to the increase in international travel, especially to and from West Africa. Several studies conducted in other extra-Amazonian regions showed different results, with a predominance of $P$. vivax following the national burden (Wanderley et al. 1994, Chaves et al. 1995, Alves et al. 2000, Bértoli \& Moitinho 2001, Machado et al. 2003,
Falavigna-Guilherme et al. 2005, Couto et al. 2010, MS/ SVS 2013). Moreover, it should be noted that four of the eight cases caused by $P$. malariae reported in RJ were autochthonous. Similarly, Couto et al. (2010) found five autochthonous cases caused by P. malariae in SP.

The number of reported cases (imported and autochthonous) in RJ did not follow the national trend. Although the number of cases increased in the first part of the study period up to 2005 , similarly to the national trend, from 2006-2010 the number of reported cases decreased $49.1 \%$ nationally, whereas in $\mathrm{RJ}$ this reduction was only $32.8 \%(\mathrm{p}=0.0000)$. Because the percentage of autochthonous cases was low (4.3\%), these results most likely reflect the increase of travellers between RJ and malaria endemic areas, both in Brazil and other countries. A similar finding was reported by Couto et al. (2010) for SP, but they found an absolute increase in autochthonous malaria cases between 2005-2007. A total of 555 (68.7\%) cases reported in this study were individuals who lived or stayed in 47 (51.1\%) municipalities of the state. Such figures are alarming, because most malaria cases are imported and these individuals could represent a source of infection for new cases (introduced malaria) in large areas of the state, especially in municipalities with a weak epidemiological surveillance system and the presence of the vector. Some evidence suggests that there is undernotification of malaria cases, but we failed to determine its actual extent (Costa et al. 2010). These results expose the need to strengthen the epidemiological surveillance system to take appropriate control measures depending on the level of endemicity.

This retrospective study identified autochthonous malaria cases in at least 12 municipalities of the state over nine years, showing that transmission has not been interrupted. Eight municipalities of RJ, with cases notified in the last years, could be characterised as areas of residual malaria. They are: Cachoeiras de Macacu, Campos dos Goytacazes, Casimiro de Abreu, Macaé, Magé, Paraty, Santa Maria Madalena and São Fidelis (Carvalho \& Rachou 1950). Malaria cases from residual areas of the Atlantic Forest reveal a stable cycle of transmission with a unique ecology; these areas most likely do not represent an epidemiologic risk for the population, which raises the possibility that malaria be a zoonosis (Curado et al. 2006, Duarte et al. 2008). Other municipalities with cases in recent years, such as Nova Friburgo, Petrópolis, Rio das Flores, Guapimirim and Sapucaia would be new foci of malaria from the Atlantic Forest system (WHO 2007). Characterisation of new foci is important because in these scenarios there is potential risk for malaria reintroduction. Four cases of $P$. falciparum malaria were notified in two municipalities in the state. Because there is no evidence from a conclusive field study, it is not possible to establish the true origin of these cases and make an effective conclusion about the transmission of P. falciparum in RJ.

The presence of vectors is a determining factor for transmission and for assessing receptivity conditions (Azevedo 1997, Rezende et al. 2009, 2013, Laporta et al. 2011, da Silva et al. 2013, Duarte et al. 2013, Neves et al. 2013). A study conducted in 2009 by the Brazilian Health System showed that several species occur in RJ. 
An. darlingi, the most efficient malaria vector in Brazil, was found in nine municipalities of the state, although 23 municipalities did not report any information (silent areas). In the same study, An. aquasalis, another important vector, was found in 30 municipalities and Anopheles albitarsis was the most widespread, being observed in all studied areas. Two other important vectors of the so-called bromeliad-malaria, Anopheles cruzii and An. bellator, were identified in 12 and 10 municipalities, respectively (Azevedo 1997, CEPA 2009). The presence of some species of competent malaria vectors, at least, in 28 municipalities of the state, raises suspicion that these areas could become receptive for reintroduction of sustainable transmission. To evaluate this question, undoubtedly entomological studies, using primary data, are a priority in RJ. New prospective studies with an entomological component must be carried out.

Several studies have reported autochthonous malaria cases in other southeastern and southern states of Brazil. Branquinho et al. (1997) reported that in 1994 there were 28 autochthonous cases in SP, where Wanderley et al. (1994) also found 410 autochthonous cases between 1983-1991. In MG, Chaves et al. (1995) observed 471 autochthonous cases between 1980-1992, whereas Limongi et al. (2008) diagnosed only one case in the same state in 2005. In PR, 851 cases of malaria were notified between 1992-2003 (Falavigna-Guilherme et al. 2005), whereas 65 autochthonous cases occurred from 2001-2004 in ES (Cerutti Jr et al. 2007).

Interestingly, it should be noted that $62.9 \%$ of the autochthonous cases in our study were reported in the first half of the year, in the hottest seasons. The biology of the parasite and mosquitoes could explain this higher prevalence and further studies are needed to elucidate this pattern. Because temperature is the major factor affecting the sporogonic cycle of malaria parasites in mosquitoes, ambient temperatures in the hottest months in RJ are optimal for Plasmodium development (WHO 2007). Sporozoites of $P$. vivax have a lower threshold (ca. $16^{\circ} \mathrm{C}$ ) than $P$. falciparum sporozoites and this difference may explain the $P$. vivax malaria cases during the coldest months in this area (WHO 2007).

A recent systematic review identified 75 malaria resurgence events in 61 countries from 1930-2000. The authors attributed the resurgence to three general categories (not mutually exclusive): the weakness of health services and malaria control programs, increases in the intrinsic potential for transmission and technical problems (e.g., drug resistance) (Cohen et al. 2012). At least two of these categories are present in RJ. Because malaria is not endemic, epidemiological and entomological surveillance for the disease is weak in the state. Moreover, migration from Africa, Haiti and the Amazon Region can lead to an increased flow of infected people to an area with malaria vectors. It should be noted that lethality is more than 70 times higher in the extra-Amazonian region (1.27\%) than in the Amazon Region, an endemic area $(0.018 \%)$ (MS/ SVS 2013). In this study, lethality was $1.23 \%$, very near the PNCM figure for malaria in the extra-Amazonian region. It has been suggested that this difference occurs because clinicians do not suspect cases of malaria outside endemic regions, resulting in delayed diagnosis and treatment. Frequently, clinicians confuse malaria with dengue, a prevalent disease in this state during the summer season (Costa et al. 2010, Oliveira-Ferreira et al. 2010).

The major limitation of this study is the analysis of secondary data which compromises the accuracy of the information and does not allow us to assess the real potential for a sustainable local transmission of the disease. However it permits us to recognise some strategies that should be adopted to estimate the real risk of malaria reintroduction in RJ: (i) improvement of the surveillance system. Each suspicious malaria case must be investigated until confirmed or discarded. The case must be diagnosed early and receive adequate treatment until parasitological cure; (ii) better field investigation to determine if the case is imported, indigenous, introduced, induced, or is a relapse; (iii) along with epidemiological surveillance, systematisation of entomological surveillance to assess the area's receptivity to malaria with vector capacity studies; (iv) greater investments in local health systems to improve community epidemiological surveillance systems; (v) the addition of ecological and climate studies, following WHO recommendations; (vi) the assessment of vulnerability and receptivity conditions is imperative to establish the real risk of malaria reintroduction in RJ. These studies should incorporate Pavlovsky's theory of the natural nidality of human diseases.

\section{ACKNOWLEDGEMENTS}

To Publicase, for medical writing services, and to VectorBorne Diseases and Zoonosis Department of the Health Service of the State of Rio de Janeiro, for surveillance data.

\section{REFERENCES}

Alves MJCP, Rangel O, Souza SSAL 2000. Malária na região de Campinas, São Paulo, Brasil, 1980 a 1994. Rev Soc Bras Med Trop 33: 53-60.

Azevedo AL 1997. Aspectos da epidemiologia da malária e da biologia de Anopheles (Kerteszia) cruzii Dyar \& Knab em vales montanhosos do sistema de Mata Atlântica, Rio de Janeiro (RJ), MsD Thesis, Instituto Oswaldo Cruz-Fiocruz, Rio de Janeiro, 150 pp.

Bértoli M, Moitinho MLR 2001. Malária no estado do Paraná, Brasil. Rev Soc Bras Med Trop 34: 43-47.

Branquinho MS, Marrelli MT, Curado I, Natal D, Barata JM, Tubaki R, Carréri-Bruno GC, de Menezes RT, Kloetzel JK 1997. Infection of Anopheles (Kerteszia) cruzii by Plasmodium vivax and Plasmodium vivax variant VK247 in the municipalities of São Vicente and Juquitiba, São Paulo. Rev Panam Salud Publica 2: 189-193.

Carvalho FF, Rachou RG 1950. Considerações sobre a malária no Estado do Rio de Janeiro com especial referência ao Vale do Rio Piraí. Rev Bras Malariol Doencas Trop 3: 473-487.

CEPA - Centro de Estudos e Pesquisa em Antropozoonoses do Estado do Rio de Janeiro Máximo da Fonseca Filho 2009. I Encontro Macrorregional de Malária do Rio de Janeiro. Available from: sms.rio.rj.gov.br/coe/Apresenta\%E7\%F5es/Mal\%E1ria/I\%20 Encontro\%20Macrorregional\%20de\%20Mal\%E1ria\%20RJ\%20 DEZ_2009.pdf.

Cerutti Jr C 2007. Caracterização epidemiológica da malária autóctone do Espírito Santo, $\mathrm{PhD}$ Thesis, Faculdade de Medicina da Universidade de São Paulo, São Paulo, 250 pp.

Cerutti Jr C, Boulos M, Coutinho AF, Hatab MCLD, Falqueto A, Rezende HR, Duarte AMRC, Collins W, Malafronte RS 2007. 
Epidemiologic aspects of the malaria transmission cycle in an area of very low incidence in Brazil. Malar J 6: 33.

Chaves KM, Zumpano JP, Resende MC, Pimenta JRFG, Rocha MOC 1995. Malária em Minas Gerais, Brasil, no período 1980-1992. Cad Saude Publica 11: 621-623.

Cohen JM, Smith DL, Cotter C, Ward A, Yamey G, Sabot OJ, Moonen B 2012. Malaria resurgence: a systematic review and assessment of its causes. Malaria J 11: 1-17.

Costa AP, Bressan CS, Pedro RS, Valls R, Silva S, Souza PR, Guaraldo L, Ferreira-da-Cruz MF, Daniel-Ribeiro CT, Brasil P 2010. Diagnóstico tardio de malária em área endêmica de dengue na extraAmazônia brasileira: experiência recente de uma unidade sentinela no Estado do Rio de Janeiro. Rev Soc Bras Med Trop 43: 571-574.

Couto RDA, Latorre MRDO, Di Santi S, Natal D 2010. Malária autóctone notificada no estado de São Paulo: aspectos clínicos e epidemiológicos de 1980 a 2007. Rev Soc Bras Med Trop 43: 52-58.

Curado I, dos Santos MR, de Castro DAM, Kirchgatter K, Branquinho MS, Bianchi GEA 2006. Malaria epidemiology in low endemicity areas of the Atlantic Forest in the Vale do Ribeira, São Paulo, Brazil. Acta Trop 100: 54-62.

da Silva KS, Pinto IS, Leite GR, das Virgens TM, dos Santos CB, Falqueto A 2013. Ecology of anopheline mosquitoes (Diptera: Culicidae) in the central Atlantic Forest biodiversity corridor, southeastern Brazil. J Med Entomol 50: 24-30.

Duarte AM, Malafronte RS, Cerutti Jr C, Curado I, de Paiva BR, Maeda AY, Yamasaki T, Summa ME, Neves DV, de Oliveira SG, Gomes AC 2008. Natural Plasmodium infections in Brazilian wild monkeys: reservoirs for human infections? Acta Trop 107: 179-185.

Duarte AM, Pereira DM, de Paula MB, Fernandes A, Urbinatti PR, Ribeiro AF, Mello MH, Matos Jr MO, Mucci LF, Fernandes LN, Natal D, Malafronte RS 2013. Natural infection in anopheline species and its implications for autochthonous malaria in the Atlantic Forest in Brazil. Parasit Vectors 6: 58.

Falavigna-Guilherme AL, Silva AM, Guilherme EV, Morais DL 2005. Retrospective study of malaria prevalence and Anopheles genus in the area of influence of the binational Itaipu reservoir. Rev Inst Med Trop Sao Paulo 47: 81-89.

Hochman G, de Mello MTB, dos Santos PRE 2002. Malaria in pictures: images from Brazil $\square \mathrm{s}$ public health campaigns in the first half of the twentieth century. Hist Cienc Saude Manguinhos 9 (Suppl.): 233-273.

IBGE - Instituto Brasileiro de Geografia e Estatística 2010. Primeiros resultados do censo 2010. Available from: ibge.gov.br/estadossat/ perfil.php?sigla $=$ rj.

INEA - Instituto Estadual do Ambiente 2011. O estado do ambiente: indicadores ambientais do Rio de Janeiro 2010, SEA/INEA, Rio de Janeiro, 76 pp.

INPE - Instituto Nacional de Pesquisas Espaciais 2013. TerraViews 4.1.0. Available from: dpi.inpe.br/terraview.

Laporta GZ, Ramos DG, Ribeiro MC, Sallum MAM 2011. Habitat suitability of Anopheles vector species and association with human malaria in the Atlantic Forest in south-eastern Brazil. Mem Inst Oswaldo Cruz 106 (Suppl. I): 239-245.

Limongi JE, Chaves KM, Paula MBC, Costa FCC, Silva AA, Lopes IS, Neto AAP, Sales JM, Rodrigues F, Resende MAMR, Ferreira MS 2008. Malaria outbreaks in a non-endemic area of Brazil. Rev Soc Bras Med Trop 41: 232-237.
Linhares S 2011. História do Estado do Rio de Janeiro. Available from: cide.rj.gov.br/cidinho.

Machado RLD, Couto AARA, Cavasini CE, Calvosa VSP 2003. Malária em região extra-amazônica: situação no estado de Santa Catarina. Rev Soc Bras Med Trop 36: 581-586.

Mattos MS, Oliveira-Ferreira J, Castro MG, Lourenço-de-Oliveira R 1993. Malária autóctone no município de Nova Friburgo - Rio de Janeiro. Proceedings of the IV Reunião Nacional dos Pesquisadores em Malária, Summary 13, Manaus, Brasil, p. 23.

Moraes HF 1990. SUCAM sua origem sua história, 2nd ed., Ministério da Saúde, Brasília, 484 pp.

MS/SVS - Ministério da Saúde/Secretaria de Vigilância em Saúde 2003. Programa Nacional de Prevenção e Controle da Malária, PNCM, MS/SVS, Brasília, 132 pp.

MS/SVS - Ministério da Saúde/Secretaria de Vigilância em Saúde 2013. Situação epidemiológica da malária no Brasil, 2000 a 2011. Bol Epidemiol 44: 1-16.

MTE - Ministério do Trabalho e Emprego 2009. Perfil Migratório do Brasil 2009. Organização Internacional para as Migrações. Available from: publications.iom.int/bookstore/free/Brazil_Profile2009.pdf.

Nelder MP, Russell C, Williams D, Johnson K, Li L, Baker SL, Marshall S, Bhanich-Supapol W, Pillai DR, Ralevski F 2013. Spatiotemporal dynamics and demographic profiles of imported Plasmodium falciparum and Plasmodium vivax infections in Ontario, Canada (1990-2009). PLoS ONE 8: e76208.

Neves A, Urbinatti PR, Malafronte RS, Fernandes A, Paganini WS, Natal D 2013. Malaria outside the Amazon Region: natural Plasmodium infection in anophelines collected near an indigenous village in the Vale do Rio Branco, Itanhaém, SP, Brazil. Acta Trop 125: 102-106.

Oliveira-Ferreira J, Lacerda MVG, Brasil P, Ladislau JLB, Tauil PL, Daniel-Ribeiro CT 2010. Malaria in Brazil: an overview. Malar J 9: 115.

Rezende HR, Falqueto A, Urbinatti PR, de Menezes RM, Natal D, Cerutti Jr C 2013. Comparative study of distribution of anopheline vectors (Diptera: Culicidae) in areas with and without malaria transmission in the highlands of an extra-Amazonian region in Brazil. J Med Entomol 50: 598-602.

Rezende HR, Soares RM, Cerutti Jr C, Alves IC, Natal D, Urbinatti PR, Yamasaki T, Falqueto A, Malafronte RS 2009. Entomological characterization and natural infection of anophelines in an area of the Atlantic Forest with autochthonous malaria cases in mountainous region of Espírito Santo state, Brazil. Neotrop Entomol 38: 272-280.

Wanderley DMV, Andrade JCR, Meneguetti LC, Chinelatto MJ, Dutra AP 1985. Malária no estado de São Paulo, Brasil, 1980 a 1983. Rev Saude Publica 19: 28-36.

Wanderley DMV, Silva RA, Andrade JCR 1994. Aspectos epidemiológicos da malária no estado de São Paulo, Brasil, 1983 a 1992. Rev Saude Publica 28: 192-197.

WHO - World Health Organization 2007. Guidelines on the elimination of residual foci of malaria transmission. Available from: applications.emro.who.int/dsaf/dsa742.pdf.

Zuckerman JN 2008. Imported malaria in the UK. BMJ 337: 62-63. 